\title{
Heat: Its measurement from Galileo to Lavoisier
}

\author{
David v. Fenby \\ Chemistry Department, The University, Glasgow, G12 8QQ, Scotland, U.K. \\ (on leave from Chemistry Department, University of Otago, Dunedin, \\ New Zealand)
}

\begin{abstract}
Professor Andrade has commented that "the modern science of heat... may be said to have originated when a really clear distinction was made between heat and temperature." This took place in the mid-18th century and is primarily associated with Black, who introduced the concepts of latent heat and heat capacity. Temperature is the intensive property, the "quality", of heat, measured with a thermometer, an instrument dating from the early 17th century; the "quantity" of heat was considered an extensive and conserved state function, analogous to the thermodynamic energy of today. In showing how heat changes could be measured, Black pioneered calorimetry. Of the many calorimetric studies in the second half of the 18th century, the most celebrated is that of Lavoisier and Laplace. In the 17 th and 18th century studies of "heat" are to be found many of the origins of thermodynamics.
\end{abstract}

\section{INTRODUCTION}

On 28 June, 1783 Laplace presented to the Académie Royale des Sciences the heat measurements that he and Lavoisier had made during the preceding winter. Their Mémoire sur la chaleur appeared in pamphlet form about a month later, and was published in the Académie's Mémoires for 1780, which appeared in 1784 (refs 1, 2). In this work Lavoisier and Laplace describe their celebrated ice calorimeter (Note a) and its application in a variety of studies. The collaboration (ref. 4) involved two of the most eminent scientists of the age: Antoine Laurent Lavoisier (1743-94), who heralded a revolution in chemistry and then was the central figure in bringing it about, until falling victim to another revolution; Pierre Simon Laplace (1749-1827), the mathematician and theoretical physicist, remembered particularly for his contributions to probability theory and celestial mechanics. In their intermittent collaborations between 1777 and 1784, Lavoisier was the senior partner, and their studies related to his research programme. The imprint of Laplace is very evident, however, both in their joint work and in Lavoisier's subsequent thought (ref. 4).

The Mémoire sur la chaleur is a classic in the history of science. The calorimetric investigation by Lavoisier and Laplace is the most famous, but by no means the first, of several such studies during the second half of the 18th century. The pioneering figure was Joseph Black (1728-99), who introduced the concepts of latent heat and heat capacity (or specific heat, as it was later called) and methods for measuring these properties. In this paper I shall consider Black's work and the background to it before proceeding to a discussion of 18th century calorimetric studies, the reasons for them and the techniques employed.

\section{THERMOMETER}

The most significant 17th century contribution to the study of heat was the appearance of the thermometer (ref. 5), a term apparently first used by Leuréchon in 1626. The first thermometers, introduced early in the century, were air thermometers, of which there were

Note a: The term calorimetre was coined by Lavoisier in 1789: "I acknowledge the name Calorimeter, which I have given [the apparatus], as derived partly from Greek and partly from Latin, is in some degree open to criticism; but, in matters of science, a slight deviation from strict etymology, for the sake of giving distinctness of idea, is excusable; and I could not derive the name entirely from Greek without approaching too near to the names of known instruments employed for other purposes (ref. 3)". 
two types: the open (Italian) and the differential (Dutch). The discovery of the former has been popularly associated with Galileo, but the evidence is inconclusive, being based on assertions by his friends and pupils. Independent discovery has also been attributed to Santorio Santorii and Robert Fludd. The first known description of an open air thermometer is that of Santorio Santorii in 1611, and the first diagram is that in the Telioux manuscript (Rome, 1611) (ref. 6). The discovery of the differential air thermometer is usually attributed to Cornelius Drebbel. Air thermometers were quite common in the second quarter of the 17th century, but, with the awareness (from the 1640s) of the variability of atmospheric pressure, the main defect of the open variety (i.e. its response to pressure as well as temperature changes) became apparent.

For liquid-in-glass thermometers, the question of discovery is less ambiguous. The open variety was invented by Jean Rey, a French doctor living in the Dordogne, before 1632 . Two sealed varieties (Florentine thermometers), the familiar liquid-in-glass model and another based on changes in liquid density with temperature, were invented by the Grand Duke Ferdinand II of Tuscany, a member of the Medici family, around the mid-17th century. Such thermometers, particularly the usual liquid-in-glass type, were widely used. Various liquids, including mercury, were tried, but initially spirit of wine was preferred because of its greater coefficient of thermal expansion. In 1713 Daniel Gabriel Fahrenheit (1686-1736) experimented with the use of mercury, and four years later he began to make mercury-in-glass thermometers commercially. These and imitations thereof soon became the most widely used model.

In the second half of the 17th century, the need for a satisfactory temperature scale was recognised; in the 1660s, for example, the Royal Society of London, Huygens, and Boyle independently referred to the importance of making thermometers comparable. An early attempt to do so was that of Robert Hooke in his Micrographia (1665); this scale was based on a single fixed point (the freezing point of water), and the degree corresponded to a particular fractional change (1/1000) in the volume of a liquid (spirit of wine). There followed a proliferation of temperature scales (refs 5,7 ); the mid-18th century saw thermometers with more than a dozen scales attached. Only three survived into the 19th century: the Réaumur, Celsius and Fahrenheit scales. These were based on two fixed points, although the first started off as a one fixed point scale. Eventually, the melting and boiling points of water became the accepted fixed points, but doubts about the constancy of these lingered well into the 18th century. In the 1690s, Halley and Amontons independently reported the constancy of the boiling point of water, but some doubted this (ref. 7). It was fairly widely believed that the freezing point of water was lower in cold climates (ref. 7).

\section{EARLY THERMOMETRIC STUDIES}

Thermometric measurements from the mid-17th to the mid-18th century yielded many, now familiar results: thermal equilibrium, thermal expansion, the constancy of melting and boiling points at constant pressure, their variations with pressure, the temperature changes accompanying many chemical reactions, the depression of the freezing point when salts are added to water, and so on. It is sometimes difficult to appreciate that such results were often controversial. I shall consider a few of the early thermometric studies, selecting those that were important in Black's work or that appear relevant in other ways to the development of calorimetry in the second half of the 18 th century.

\section{Accademia del Cimento}

Between 1657 and 1667 there existed in Florence a small experimental group, the Accademia del Cimento, defenders of the Galileo tradition in the face of the predominant Aristotelian dogma (ref. 8). Its founders and protectors were two Medici brothers, Prince Leopold and the Grand Duke Ferdinand II, both of whom were also participants. Some of the group's experimental results were published in its Saggi di naturali esperienze (1667) (ref. 8).

The Accademia del Cimento observed the boiling of lukewarm water under vacuum (an experiment carried out by Boyle a few years previously), the expansion of water on freezing, the thermal expansion of solids, the maximum density of water [an observation that Boyle was unable to confirm, and that Hooke refused to believe; the temperature of water at its maximum density was measured early in the 19th century by Hope (ref.9)]. The group weighed hot and cold objects to see if heat, which they believed to be a substance, had mass; such measurements were still being made almost 150 years later by count Rumford, with equally ambiguous results. (The measurement of heat by weighing it was not a fruitful approach!) The first "calorimetric" measurements known to me were made by the Accademia in 1667, although not reported in the Saggi (ref. 8):

(1) To determine "the degree of heat that keeps tin melted" (ref. 8), some tin was melted, added to water and the temperature rise measured.

(2) A similar experiment was carried out with iron heated until it would ignite sulphur.

(3) Into a jar of concentrated nitric acid, sitting in a larger jar containing water, tin filings were added and, when reaction was complete, the temperature rise in the water noted. These experiments are of interest with respect to the development of both the method of 
mixtures and the adiabatic water calorimeter in the next century. Finally, the observation that a thermometer sitting in sunlight soon reached a steady temperature was attributed to the fact that "it is getting just as much heat as is escaping (ref. 8)", an early allusion to a conservation of heat principle.

\section{Fahrenheit}

Black, in introducing latent heat and heat capacity, referred to two experimental studies carried out by Fahrenheit in the 1720s:

(1) Fahrenheit was the first to observe the freezing of supercooled water (ref. 10), noting that, when this takes place, the temperature rises abruptly to $32{ }^{\circ} \mathrm{F}$. About 30 years later, Black asked where the heat required to bring about this temperature increase came from.

(2) At Boerhaave's suggestion, Fahrenheit mixed water and mercury at known different temperatures and then measured the temperature of the final system. (This sort of mixing experiment later became the method of mixtures for determining relative heat capacities.) Boerhaave was interested in the distribution of heat, which he considered a substance, among bodies in thermal equilibrium. He concluded, on the basis of Fahrenheit's mixing experiments, that it was distributed between bodies "in proportion to their bulk, or extension [i.e. volume], and not of their density (ref. 11)". Black pointed out that the experimental results were in fact incompatible with distribution proportioned to volume or to density; he interpreted Fahrenheit's work in terms of the different heat capacities of water and mercury.

Experiments involving the mixing of the same liquid (usually water) at different temperatures were common in the 18th century (ref. 12). Many of these related to the reliability of mercury-in-glass thermometers: do equal volume increments of mercury indicate equal heat inputs? In the calorimetric studies of the second half of the 18th century, this was seen as an important question. The usual way to "check" thermometers was to mix equal volumes of water at different temperatures, and then compare the final temperature with the arithmetic mean of the initial temperatures. Such measurements by Brook Taylor, Black, Crawford, Deluc and others showed that the mercury thermometer is an "accurate measure of heat (ref. 13)", but that some other liquids would be unsatisfactory as thermometric substances.

\section{Martine}

Between 1738 and 1740, George Martine (1702-41), a Scottish doctor, published essays on thermometry and heat (ref. 7). Some of his experiments concerned the rates at which different substances heat and cool. The accepted and "plausible (ref. 7)" view, supported by Boerhaave and Musschenbroek, was that these rates were inversely related to densities. Martine's measurements did not support this; for example, he compared the heating (and cooling) rates of equal volumes of water and mercury, and found "that water, instead of acquiring or losing a given quantity of heat 13 or 14 times sooner than Quicksilver, as it should do by the common theory, is about twice so slow in heating and cooling than what Mercury was found to be (ref. 7)". He added to this evidence against the "common theory" with measurements on oil, spirit of wine, and "Common Brandy". Black interpreted the relative heating (and cooling) rates of water and mercury in terms of their different heat capacities.

\section{HEAT}

\section{What is heat?}

Until the second half of the 19th century, there were, very broadly speaking, two views concerning the nature of heat:

(1) Material theories. These have their origin in the doctrine of the four elements (earth, water, air, fire), which is generally credited to Empedocles. The culmination of this view was caloric, the matter of fire, and Lavoisier's inclusion of this substance in his table of elements (ref. 3); the rise and fall of the caloric theory has been considered in detail by Fox (ref. 14). In the second half of the 18th century, there was a widespread belief that heat was an imponderable fluid; sometimes this fluid was assumed to be made up of particles which repelled one another but were attracted to the particles of ordinary matter.

(2) Mechanical theories. The view that heat arises from the motions of the constituent particles of matter also has a Greek pedigree. Its first "modern" adumbration was by Girolamo Cardano in the 16th century, and the idea was elaborated by Francis Bacon in his Novum Organum (1620). Newton, in his Opticks, believed that heat may be caused by a "vibrating motion" of the constituent parts of bodies. The first mathematical expression of the mechanical view was that of Daniel Bernoulli in Hydrodynamica (1738); a summary of this was included in Deluc's Recherches sur les modifications de l'atmosphère (1772), a well known book in the late 18th century. Lavoisier and Laplace, in discussing various opinions concerning the nature of heat (refs 1, 2), mentioned a mechanical hypothesis in which "heat is the vis viva [mass $\mathrm{x}$ velocity ${ }^{2}$ ] resulting from the imperceptible motions of the constituent particles of a body (ref. 2)". Given Lavoisier's preference for a material heat, this view was presumably that of Laplace, arising, in the opinion of Guerlac (ref. 4), from an awareness of Bernoulli's work obtained via Deluc. 
In statements concerning the nature of heat, Black was cautious [elsewhere (ref. 15) I have associated this with scottish philosophical opinion at the time], but he was not neutral, and inclined to a material view (ref. 16). Black realised and emphasized, however, that heat could be measured irrespective of what it is; Crawford (ref. 13) and Lavoisier and Laplace (refs 1, 2) later expressed the same view. Consequently, phenomenological progress was possible even if final causes were unknown.

\section{Conservation of heat}

The assumption that heat is conserved was common, although usually implicit, from the 17th century to the mid-19th century, when it was replaced by the conservation of energy. It was accepted by proponents of both views concerning the nature of heat, and was not peculiar to those supporting a material hypothesis. In Laplace's mechanical model mentioned above, for example, a conservation of heat is a necessary consequence of the conservation of vis viva, which was widely accepted at the time. Lavoisier and Laplace also emphasized the

"reversible" nature of heat: "All changes in heat... suffered by a system of bodies during a change of state recur in the opposite sense when the system returns to its original state (ref. 2)". In the second half of the 18th century, if we leave aside the question of its cause, heat was considered a property of a system analogous to (thermodynamic) energy; it was a conserved state function. Much of the writing of the time becomes decidedly "modern" when the word "heat" is replaced by "energy".

\section{BLACK}

\section{Introduction}

Joseph Black's outstanding achievements were:

(1) His M.D. dissertation work at Edinburgh on causticity and alkaline substances; this

involved the "discovery" of fixed air (carbon dioxide) as a gas chemically distinct from air.

(2) His studies on heat, carried out between 1756 and 1766 at the University of Glasgow.

At the beginning of the 18th century, at least in Britain, the universe was seen as a Newtonian construct, a world of "particles", ranging in size from the invisible to planets, interacting via centralised forces. Newton's triumph was the application of this model to the astronomical world using gravitational forces, but, in his opticks, he, also proposed a research programme for his successors: the extension of the interacting particle model to other phenomena, including chemical reactivity. Here Newton recognised the difficulties; chemical reactions between substances can be profoundly altered by the presence of a third substance, and hence the force law between reactant particles must involve more than mass and distance. This Newtonian programme attracted much attention in the first half of the 18 th century, especially with chemical and physiological phenomena, but around mid-century it came to be seen as a quantitative failure. Nevertheless, many continued to view the model as essentially correct, even if sterile. As I shall discuss later, it reappears in the work of Lavoisier and Laplace (refs 1, 2). In the second half of the 18th century, mechanical explanations were increasingly replaced by material causes; it was the age of the imponderable fluids. These too had a Newtonian respectability, following Newton's suggestion that gravitation could be accounted for by invoking that mysterious substance, the aether. [The drift from mechanical to material explanations during the 18 th century is discussed by Schofield (ref. 17).]

William Cullen (1710-90) placed aether at the centre of his chemistry and medicine (ref. 18). He attempted to explain the selectivity of chemical reactions in terms of differing aether densities surrounding the reacting particles. The problem was to obtain quantitative information about these densities, and Cullen believed that he could do so by measuring the temperature changes accompanying chemical reactions. His experiments inadvertently led to the discovery of cooling by evaporation when a student observed a temperature drop on removing a thermometer from a volatile liquid. A series of measurements, including some under vacuum, of this phenomenon followed (ref. 19). Cullen's thermometric studies are important for several reasons: his attempt to predict chemical reactivity from thermometric measurements; the discovery of cooling by evaporation (others independently observed this); his role in attracting the interest of Black, his pupil, friend and successor, to the study of heat.

\section{Latent heat}

Fahrenheit (ref. 10) had observed the rapid temperature rise to $32^{\circ} \mathrm{F}$ when supercooled water freezes. Black proposed that the heat required to bring about this temperature increase comes from the phase change itself; he asked, "Is not this the heat that is unnecessary to ice? (ref. 20)". With respect to the melting of ice, the accepted view was that, on being warmed to the melting point, only a tiny further addition of heat was required to melt all the ice. His attention having been focused by Fahrenheit's observation, Black realised that many common phenomena are inconsistent with this view (ref. 21); for example, ice and snow do not melt as soon as the ambient temperature exceeds the melting point. Black proposed that the melting of ice involves the absorption of a considerable quantity of heat, which, because 
it does not alter the temperature, he called latent heat. Conversely, when water freezes, the latent heat is evolved. Black later applied the latent heat concept to the boiling of water and, in general, to the melting and vaporization of all substances.

Black saw latent heat as a theory of fluidity: "I would lay it down as a general and fixed rule, that fluids retain their fluidity by heat, and lose it, when, by any means they are deprived of that heat (ref. 22)". He envisaged some sort of chemical interaction involving heat: "The heat... is in [the vapour], probably united to every particle, as one of the ingredients of its vaporous constitution. And as ice, united with a certain quantity of heat, is water, so water, united with another quantity of heat, is steam or vapour (ref. 21)". Heat became a chemical component, one that determines the physical state of a substance. (Lavoisier independently proposed the same idea a few years later.)

While he developed the idea and lectured on latent heat soon after his return to Glasgow in 1756, it was not until five years later that Black and his students measured the property (ref. 20). Several methods were used (refs 12, 20, 21):

(1) Equal masses of $\mathrm{H}_{2} \mathrm{O}(\ell)$ and $\mathrm{H}_{2} \mathrm{O}(\mathrm{s})$, both initially at the freezing point, were suspended in a warm room. From the rate of temperature rise of the $\mathrm{H}_{2} \mathrm{O}(l)\left(\mathrm{e} \cdot \mathrm{g} \cdot 14^{\circ} \mathrm{F} \mathrm{h}^{-1}\right.$ ) and the time required to melt the ice $(\mathrm{e} . \mathrm{g} .10 \mathrm{~h})$, Black obtained the latent heat of fusion, expressed as the temperature rise that an equal quantity of heat would produce in an equal mass of $\mathrm{H}_{2} \mathrm{O}(l)$ (e.g. $\left.140^{\circ} \mathrm{F}\right)$. A similar approach was applied to obtain the latent heat of vaporization of water: placing a quantity of water at a known temperature on a stove, Black measured the time required to heat the water to its boiling point and then the time for it to boil away. (2) On mixing equal masses of $\mathrm{H}_{2} \mathrm{O}(l)$ at its boiling point and $\mathrm{H}_{2} \mathrm{O}(\mathrm{s})$ at its freezing point, Black obtained water at $50^{\circ} \mathrm{F}$. This gave a latent heat of fusion equal to the heat required to raise the temperature of an equal mass of $\mathrm{H}_{2} \mathrm{O}(l)$ by $144{ }^{\circ} \mathrm{F}$, in good agreement with the value above. (The average of Black's values corresponds to $5.9 \mathrm{~kJ}$ mol-1, compared to today's literature value of $6.0 \mathrm{~kJ} \mathrm{~mol}^{-1}$.) Johan Carl Wilcke (1732-96) independently discovered the latent heat of fusion of water almost twenty years after Black, and he measured this property by mixing water and snow (ref. 12). James Watt (1736-1819), at the time a mathematical instrument maker at the University of Glasgow, measured the latent heat of vaporization of water using a similar technique: a known mass of steam was condensed in a known mass of cold water and the resulting temperature increase measured (ref. 23).

(3) Beginning in 1764, Black and Irvine measured the latent heat of vaporization of water by distilling a known quantity of $\mathrm{H}_{2} \mathrm{O}(l)$ using a condenser containing another known mass of $\mathrm{H}_{2} \mathrm{O}(\ell)$. Their results were about $15 \%$ low, but watt later obtained better values. (Watt's interest in this property arose from his efforts to improve the steam engine; he later measured the pressure variation of the latent heat of vaporization of water.)

Early latent heat measurements usually involved water, but Black and Irvine also measured the latent heats of fusion of spermaceti, beeswax and tin.

\section{Heat capacity}

Black interpreted the water/mercury experiments of Fahrenheit and of Martine in terms of the different heat capacities of water and mercury: different quantities of heat are required to raise the temperatures of equal volumes (or equal masses) of different substances by one degree. He insisted that these different "capacities" for heat are characteristic properties of substances.

Watt was the first to measure heat capacities. He recognised their practical relevance to his efforts to improve the Newcomen engine. In about 1764, Black, later assisted by Irvine, began heat capacity measurements, and, following his departure for Edinburgh in 1766, this work was continued by Irvine (ref. 24). These and other early measurements [Kirwan (ref. 25), Crawford (refs 13, 26), Wilcke (ref. 12), Gadolin (ref.12)] used the method of mixtures: by mixing known quantities of two (non-reacting) substances at known different temperatures and then measuring the temperature of the resulting system, the ratio of their heat capacities is obtained. In cases where chemical interaction was a problem, a third substance was used [e.g. Irvine (ref. 24) used pounded glass]. Heat capacities (referred to both equal volumes and equal masses) were usually expressed relative to $\mathrm{H}_{2} \mathrm{O}(\ell)$. Magellan (ref. 25) published the first table of heat capacities or specific heats, as he was the first to call them, in 1780; this table included values obtained by Kirwan and Crawford.

\section{An assessment}

Black placed heat at the centre of his chemistry, which he defined as "the Study of the effects of Heat \& Mixture on Bodies and Mixtures of Bodies (ref. 20)". Previously, heat had usually been regarded as a chemical "instrument" (i.e. as something essential for many chemical changes, but without being directly involved in those changes); see, for example, Boerhaave (ref. 11). For Black (and Lavoisier) heat could act as a chemical species.

Andrade commented that "the modern science of heat... may be said to have originated when a really clear distinction was made between heat and temperature (ref. 12)". The failure to distinguish between the intensive and extensive measures of heat, or, to use Black's terms, 
between the "quality" and the "quantity" of heat, resulted in considerable confusion during the century or so preceding Black. The thermometer was being widely used, but what was the thermometer measuring? Some said heat, most were ambiguous. With Black, the intensive/ extensive distinction is clearly stated. The intensive property is temperature, measured using a thermometer. For Black and others during the second half of the 18th century, the extensive property was the total quantity of heat, be it material or mechanical, in a body. In showing how changes in this quantity could be obtained experimentally, Black pioneered calorimetry.

Black's innovations were not based on his own experimental work. Such measurements of latent heats and heat capacities that he and his students did make were to a large extent stimulated by Watt, who fully recognised the practical importance of these properties. Black and Watt were lifelong friends (ref. 23), and certainly, while at the University of Glasgow, Black assisted and encouraged Watt. However, the frequent claim that watt thought of the separate condenser (his greatest contribution to the development of the steam engine) on learning about latent heat from Black has been convincingly repudiated in recent years (ref. 20).

Black presented his ideas concerning heat in his chemistry courses and to the Glasgow Literary Society, but he published nothing on the subject. An anonymous and presumably unauthorised version of his lectures on heat appeared in 1770 (ref. 22). The usual source of information concerning Black's views on chemistry is his Lectures, edited after his death by John Robison, his pupil, friend and successor. As Christie (ref. 27) has recently shown, however, the use of this work requires caution because of Robison's various prejudices. In studying Black, it is preferable to refer to manuscripts of student notes from his lectures; a list of these has been compiled (ref. 28).

\section{IRVINE; CRAWFORD}

\section{Irvine theory}

In the 1770s, William Irvine (1743-87), who had studied with Black and acted as his experimental assistant, produced a theory "remarkable for its simplicity (ref. 24)" and its wide explanatory power. He proposed that the temperature changes accompanying chemical processes and the heat transfers accompanying (constant temperature) phase changes (i.e., latent heats) arise entirely from heat capacity differences. For example, the temperature rise when water and concentrated sulphuric acid are mixed was attributed to the fact that the heat capacity of the resulting solution is less than the combined heat capacities of the components, and the latent heat of fusion of water was attributed to the fact that the heat capacity of $\mathrm{H}_{2} \mathrm{O}(\mathrm{s})$ is less than that of $\mathrm{H}_{2} \mathrm{O}(l)$. The theory was based on the assumption that the heat capacity $\mathrm{C}$ of a substance (in a particular phase) is temperature independent; accordingly,

$$
C=Q / \theta
$$

in which $Q$ is the total quantity of heat in the sample, and $\theta$ is the temperature, based on a scale in which $\theta=0$ corresponds to a total absence of heat.

Irvine's measurements of the heat capacities of $\mathrm{H}_{2} \mathrm{O}(\mathrm{s})$, concentrated sulphuric acid and sulphuric acid solutions were qualitatively consistent with his theory (ref. 24). Using the method of mixtures with water at different temperatures, Crawford concluded that the heat capacities of metals and other solids do not vary with temperature (ref. 13). He also reported heat capacity and thermometric measurements carried out by Gadolin in Sweden; these were believed to support the Irvine theory. An interesting approach to testing this theory was to compare various estimates of the absolute zero of temperature (i.e. the temperature corresponding to a complete absence of heat). From the relative heat capacities of $\mathrm{H}_{2} \mathrm{O}(\mathrm{s})$ and $\mathrm{H}_{2} \mathrm{O}(\ell)$ and the latent heat of fusion of water, Gadolin (ref. 13) obtained about $-1400^{\circ} \mathrm{F}$; from the relative heat capacities of $\mathrm{O}_{2}(\mathrm{~g})$ and $\mathrm{H}_{2}(\mathrm{~g})$ and his heat of combustion of $\mathrm{H}_{2}(\mathrm{~g})$, Crawford (ref. 13) obtained $-1500^{\circ} \mathrm{F}$. Crawford concluded: "There is, therefore, the utmost reason to believe that the lowest degree of heat, or the point of total privation, as calculated from trials upon different bodies, according to the rule proposed by Dr. Irvine, is constant; and it is probable that this point is nearly $1500^{\circ}$ below the beginning of Fahrenheit's scale (ref. 13)". However, the agreement between the Gadolin and Crawford values of "the lowest degree of heat" was fortuitous. Such calculations are extremely sensitive to uncertainties in heat capacities; for example, an uncertainty of $5 \%$ in the ratio of the heat capacity of $\mathrm{H}_{2} \mathrm{O}(\mathrm{s})$ to that of $\mathrm{H}_{2} \mathrm{O}(l)$ leads to an uncertainty of about $30 \%$ in the calculated absolute zero. Experimental accuracy was not sufficient to provide a quantitative test of the Irvine theory. Lavoisier and Laplace realised this; their experiments gave "poor agreement" among five estimates of the absolute zero, "But one should note that a small alteration, at the most of a $40 \mathrm{th}$, in the value of the specific heats we have used, is enough to make all our results agree" and, since "we cannot reply that such a tiny error did not slip into our experiments", the results "are therefore neither favorable nor opposed to this theory (ref. 2)".

Irvine, like Black, did not publish his work on heat; in the words of his son, "he trusted for the promulgation of his doctrines to teaching them; a mode which ample experience has 
shewn to be at once injurious to the claims of the inventor and to the progress of science (ref. 24)". His views were edited by his son eighteen years after his death (ref. 24), but, prior to this, Crawford's publications (refs 13, 26) and others had brought the Irvine theory to the attention of the scientific world. This theory, with its simplicity and generality, was influential at the end of the 18th century; interestingly, its last proponent of note was John Dalton in his New System of Chemical Philosophy (1808). It did not attribute any chemical role to heat, and so, unlike the "chemical" theories of Black and Lavoisier, it did not "explain" the existence of the liquid and gaseous states of matter. Although not accepted by Black, Lavoisier, Thomson and others, the Irvine theory had a considerable impact, largely through the work of Crawford.

\section{Crawford theory of animal heat}

Adair Crawford (1748-95), having attended Irvine's chemistry course at the University of Glasgow in 1776-7, used the Irvine theory as the basis of an explanation of animal heat (i.e. the heat generated by warm-blooded animals which enables them to maintain fairly constant body temperatures greater than normal ambient temperatures). His theory and the initial experimental evidence, obtained at Glasgow in 1777, were published two years later (ref. 26). Criticism of the experimental work led to further measurements in London, and Crawford, while admitting that he had made "considerable mistakes", maintained that his explanation of animal heat remained unaffected. A second edition of his book, incorporating the new work, appeared in 1788 (ref. 13).

The animal heat theories of Crawford and Lavoisier, developed independently at about the same time, are similar (refs 29, 30). The conversion of oxygen to carbon dioxide and water during respiration releases heat that was initially in the oxygen. This was assumed to take place in the lungs, where the heat is absorbed by the blood and carried throughout the body. The two theories differ primarily in the heat transfer mechanisms proposed: for Crawford, following Irvine, all heat transfers arise because of heat capacity differences; Lavoisier believed that heat was chemically involved.

According to the Irvine theory, eqn (1), the ratio of the total quantities of heat in two bodies (at the same temperature) equals the ratio of their heat capacities, and, consequently Crawford supported his ideas with heat capacity and other calorimetric measurements:

(1) Heat capacities of oxygen, carbon dioxide, hydrogen, air. Central in the experimental evidence adduced in support of the theory were the heat capacities of oxygen, carbon dioxide and water vapour. Crawford was the first to attempt the measurement of the heat capacities of gases. Initially (ref. 26) he used a direct application of the method of mixtures, immersing warm gas, contained in a bladder, in water; he later realised that the results were "liable to much uncertainty (ref. 13)". He also tried a flow calorimetric approach, but without success. Finally, Crawford used a differential method of mixtures: two gases, contained in identical, thin-walled brass cylinders, were heated simultaneously and then quickly immersed in identical vessels containing equal volumes of water (or oil), initially at the same temperature. The ratio of the heat capacities of the gases was related to the temperature difference between the water (or oil) in the two vessels. (The instrument was called an aerometer.) Crawford's results support this theory. The work shows considerable experimental acumen, but it was not appreciated that the combination of very small

temperature differences and fairly large corrections rendered the results insignificant. (The heat capacities of gases obtained in 1812 by Delaroche and Bérard showed that the Crawford theory is untenable.)

(2) Heat capacity of water vapour. Crawford obtained a value for this by combining the total quantities of heat in oxygen and hydrogen with the heat of combustion of hydrogen, the last being measured, following Priestley's suggestion, with what we would now call a bomb calorimeter (ref. 13).

(3) The heat capacities of arterial and venous bloods were measured using the method of mixtures.

(4) Crawford also used the method of mixtures to show that the heat capacities of many substances increase upon combustion or calcination.

(5) He used an adiabatic calorimeter to measure animal heat and the heats of combustion of charcoal and wax. The instrumental design, so familiar today, is still linked with Crawford's name in the physiological literature (see, for example, ref. 31).

The details of Crawford's theory and his many experimental results are not relevant here. The range of calorimetric techniques that he used is impressive. In the 18th century Crawford's work had a significant impact; unlike Black and Irvine, he did publish his findings.

\section{LAVOISIER}

\section{Role of heat}

Heat formed an integral part of Lavoisier's chemistry; Morris claims that the "caloric theory was indeed the foundation stone upon which Lavoisier erected the new chemistry (ref. 32)". 
His explanation of combustion and calcination centred on the chemical involvement of air and later, following Priestley's discovery of the gas, of oxygen. To account for the heat and flame familiar in combustion reactions, Lavoisier assumed that oxygen gas contains a large quantity of heat, some or all of which is released during oxidation.

Manuscript evidence (ref. 32) shows that as early as 1766 Lavoisier was interested in vaporization and, in particular, in the heat absorption accompanying this process. This led him to consider water vapour, for example, as a compound of liquid water and "matter of fire" [or caloric as it was later called (ref. 33)]; this chemically combined caloric, unlike free caloric, did not influence temperature. Lavoisier went further and proposed that air is similarly a compound of some base and caloric, a view that he later (refs 3, 33) incorporated into the new chemical nomenclature and his table of elements (e.g. oxygen gas was a compound made up of two elements; a base, called oxygen, and caloric). For Lavoisier, there was no fundamental difference between vapours and permanent gases, only a difference in boiling points, and phase changes were simply chemical reactions involving the element caloric. The first collaboration between Lavoisier and Laplace in 1777 was an experimental study of vaporization (ref. 4). In the same year, Lavoisier presented his views on the chemical role of heat and his oxidation theory to the Académie Royale des Sciences, although these were not published until 1780 .

A brief account of Black's work was read to the Académie in August, 1772 and published a month later (ref. 34). This discussed only the latent heat of fusion of water, however, and did not refer to heat capacity. Lavoisier responded with a short paper (ref. 35) reporting his own accidental discovery of the latent heat of fusion of water. At this stage he was unaware of the extent and significance of Black's work, which he saw simply as confirmation of his own ideas. This situation changed in 1780-1 with the appearance in France of several books which made reference to the contributions of Black, Irvine, Crawford, Kirwan, Wilcke, and others: a French translation (1780) of Leslie's A Philosophical Inquiry into the Cause of Animal Heat (London, 1778); Guyton de Morveau's translation (1780-85) of Bergman's Opuscula physica et chemica (Stockholm, 1779); Chevalier Landriani's Opuscoli Fisico-Chimici (Milan, 1781); Baron de Dietrich's translation (1781) of Scheele's Chemische Abhandlung von der Luft und dem Feuer (Upsala and Leipzig, 1777); the publication in France (1781) of Magellan's Essai sur la nouvelle théorie du feu élémentaire, et de la chaleur des corps (London, 1780). In the last, the emphasis is on heat capacities (in fact, Magellan used the term chaleur spécifique for the first time); the work lavishly praises Crawford, but also refers to Black. Deluc recollected (ref. 32) that Magellan's Essai caused "great agitation" in Paris. This was hardly surprising. Lavoisier realised that Crawford's combustion theory was similar to his own (and that he had been anticipated in print), and he became aware of an alternative hypothesis (i.e. the Irvine theory, with its promise of quantification via heat capacity measurements) regarding the role of heat. Guerlac has concluded that, "There can be little doubt that it was Crawford's book, or rather Magellan's exposition of it, that launched Laplace and Lavoisier on... their joint work on calorimetry (ref. 4)." In the Mémoire sur la chaleur Crawford's name appears several times, and the work was perceived as a repetition of Crawford's investigations.

\section{Ice calorimeter}

Having concluded that the method of mixtures "is subject to a large number of disadvantages which can cause appreciable errors in the results (ref. 2)", Lavoisier and Laplace designed an ice calorimeter in which the heat evolved in some process was measured by the mass of ice that it melted. Lavoisier (ref. 3) attributed the principle of the apparatus to his younger colleague. In the winter of 1782-3, ice calorimeters were used to measure the heat capacities of solids, liquids and solutions, heats of mixing, solution, reaction and combustion, and the heat evolved by a guinea pig (refs 1, 2). During the following winter, further heat capacities and heats of combustion were measured, but the results were not published until 1793 (ref. 36). Laplace and Lavoisier proposed (refs 1, 2) and used (ref. 36) a flow calorimeter to measure the heat capacities of gases; their results differed from those reported by Crawford.

An interesting feature of the Lavoisier/Laplace calorimetric work was the attempt to assess the reliability of their results. In Paris during the 1770 s there was considerable interest in the problem of accurate measurement and the "theory of error". Laplace was prominent in this field, and his influence is evident in the Mémoire; for example, the authors claim, without giving details, that they "can answer for the accuracy of [their] experiments on the specific heats of bodies to close to 1 part in 40, and even to 1 part in 60 (ref. 2)". (On the other hand, this did not prevent them from using up to six figures in quoting their heat capacities.)

Lavoisier and Laplace stressed "that it is less the result of our experiments than the method we have used that we offer to scientists, inviting them, if this method seems to offer some advantage, to check these experiments which we ourselves propose to repeat with the greatest care (ref. 2)". Others did make use of ice calorimeters. One of the first to do so was Wedgwood (ref. 37), who was interested in relating his clay pyrometer scale to the Fahrenheit scale, but he abandoned the instrument. Lodwig and Smeaton (ref. 38) have discussed the 
criticism and support of the Lavoisier/Laplace ice calorimeter at the end of the 18th century and early in the 19th century. By the 1820s, adiabatic water calorimeters were widely preferred. Herschel and Bunsen independently revived the ice calorimeter but in their instruments the heat evolved was measured by the volume decrease as the ice melts (ref. 38).

\section{Mémoire sur la chaleur}

Lavoisier and Laplace concluded, on the basis of their results and some obtained by Kirwan, that the "knowledge of the specific heats of substances and of their reaction products cannot... predict the heat they should develop when they combine (ref. 2)". But, as pointed out above, there was a cautionary note: "The precision with which it is necessary to know the specific heats of bodies makes it very difficult to test the [Irvine] theory (ref. 2)". On theoretical grounds they suggested that "it is very probable that the specific heats of bodies increase with their temperature, but according to different laws for each of them (ref. 2)". Although Lavoisier and Laplace concluded against the Irvine theory, they by no means entirely rejected it. In particular, they accepted a relationship between heat capacity and heat content, using the idea to explain several phenomena; for example, in their discussion of animal heat, they used Crawford's view, relating heat transfer to and from the blood to heat capacity differences.

The Mémoire includes an intriguing suggestion: "The equilibrium between the heat, which tends to separate the particles of bodies, and their mutual affinities, which tend to bring them together, can furnish a very precise means of comparing these affinities with each other (ref. 2)". This has been attributed to Laplace (ref. 4), and it is certainly consistent with his Newtonian outlook. However, as Morris (ref. 32) has shown, this interacting particle model became increasingly significant in Lavoisier's work. What seems to be implied in the quoted sentence is the use of calorimetric measurements to obtain quantitative information about chemical reactivity; this was about 100 years prior to chemical thermodynamics. Perhaps this is to read too much into the statement; unfortunately a promised "special memoir" on the topic was never published.

\section{REFERENCES}

1. A.L. Lavoisier and P.S. Laplace, Mém. Acad. Roy. Sci., 355-408 (1780).

2. H. Guerlac, Memoir on Heat, translated with an Introduction and Notes, Neale Watson, New York (1982).

3. A.L. Lavoisier, Traité élémentaire de chimie, Paris (1789). English translation by R. Kerr, William Creech, Edinburgh (1790).

4. H. Guerlac, Hist. Studies in the Phys. Sciences 7, 193-276 (1976).

5. W.E. Knowles Middleton, A History of the Thermometer and its Use in Meteorology, John Hopkins Press, Baltimore (1966).

6. J.A. Chaldecott, Annals of Science 8, 195-201 (1952).

7. G. Martine, Essays Medical and Philosophical, A. Millar, London (1740).

8. W.E. Knowles Middleton, The Experimenters, A Study of the Accademia del Cimento, John Hopkins Press, Baltimore and London (1971).

9. T.C. Hope, Trans. Roy. Soc. Edin. 5, 379-405 (1805).

10. D.G. Fahrenheit, Phil. Trans. 33, 78-84 (1724).

11. H. Boerhaave, A New Method of Chemistry (translated by P. Shaw) 3rd ed., Longman, London (1753).

12. D. McKie and N.H.V. Heathcote, The Discovery of Specific and Latent Heats, Edward Arnold, London (1935).

13. A. Crawford, Experiments and Observations on Animal Heat, and the Inflammation of Combustible Bodies, 2nd ed., Johnson, London (1788).

14. R. Fox, The Caloric Theory of Gases from Lavoisier to Regnault, Clarendon Press, Oxford (1971).

15. D.V. Fenby, Chemistry in Britain, in press (1986).

16. J.R.R. Christie in G.N. Cantor and M.J.S. Hodge (eds), Conceptions of Ether, Studies in the History of Ether Theories 1740-1900, University Press, Cambridge (1981).

17. R.E. Schofield, Mechanism and Materialism: British Natural Philosophy in an Age of Reason, University Press, Princeton (1970).

18. A.L. Donovan, Philosophical Chemistry in the Scottish Enlightenment, University Press, Edinburgh (1975)

19. W. Cullen, Essays and Observations, Physical and Literary, Read before a Society in Edinburgh 2, 145-56 (1756).

20. H. Guerlac in A.D.C. Simpson (ed.), Joseph Black 1728-1799, Royal Scottish Museum, Edinburgh (1982).

21. J. Black, Lectures on the Elements of Chemistry (J. Robison, editor), Edinburgh (1803).

22. An Enquiry into the General Effects of Heat; with Observations on the Theories of Mixture Nourse, London (1770).

23. E. Robinson and D. McKie (eds), Partners in Science, Constable, London (1968).

24. W. Irvine and W. Irvine, Essays chiefly on Chemical Subjects, Mawman, London (1805).

25. J.H. de Magellan, Essai sur la Nouvelle Théorie du Feu Elémentaire, et de la Chaleur des Corps, London $(1780)$. 
26. A. Crawford, Experiments and Observations on Animal Heat, and the Inflammation of Combustible Bodies, Murry; Sewell, London (1779).

27. J.R.R. Christie in A.D.C. Simpson (ed.), Joseph Black 1728-1799, Royal Scottish Museum, Edinburgh (1982).

28. W.A. Cole in A.D.C. Simpson (ed.), Joseph Black 1728-1799, Royal Scottish Museum, Edinburgh (1982).

29. E. Mendelsohn, Heat and Life, Harvard University Press, Cambridge, Massachusetts (1964).

30. D.V. Fenby, Glasgow Medicine, in press (1986).

31. S.A. Richards, Temperature Regulation, Wykeham, London and Winchester (1973).

32. R.J. Morris, Brit. J. Hist. Sci. 6, 1-38 (1972).

33. L.B. Guyton de Morveau et al., Méthode de Nomenclature Chimique proposée par M M. de Morveau, Lavoisier, Bertholet, \& de Fourcroy, Paris (1787).

34. Introduction aux Observations sur la Physique 2, 428-31 (1772).

35. A.L. Lavoisier, Introduction aux Observations sur la Physique 2, 510-1 (1772).

36. P.S. de Laplace and A.L. Lavoisier, Recueil des Memoires de Chímie de Lavoisier 1,121 (1793).

37. J. Wedgwood, Phil. Trans. 74, 358-84 (1784).

38. T.H. Lodwig and W.A. Smeaton, Annals of Science 31, 1-18 (1974). 